\title{
Novel Capture Processes
}

L.I. Eide' ${ }^{1}$ M. Anheden², A. Lyngfelt ${ }^{3}$, C. Abanades ${ }^{4}$, M. Younes ${ }^{5}$, D. Clodic ${ }^{5}$, A.A. Bill6, P.H.M. Feron ${ }^{7}$, A. Rojey ${ }^{8}$ and F. Giroudière ${ }^{7}$

1 Hydro Oil \& Energy, N-0246 Oslo - Norway

2 Vattenfall Utveckling $A B, 16287$ Stockholm - Suède

3 Chalmers University of Technology, 41296 Göteborg - Sweden

4 Instituto Nacional del Carbon-CSIC, Francisco Pintado, FE 26, 33011 Oviedo - Spain

5 ARMINES, Centre Énergétique et Procédés, 60, boulevard Saint-Michel, 75272 Paris Cedex 06 - France

6 Alstom Power, Environmental Control Systems, 3, avenue André Malraux, 92309 Levallois-Perret Cedex - France

7 TNO Science and Industry, PO Box 342, 7300 AH Apeldoorn - The Netherlands

8 Institut français du pétrole, 1 et 4, avenue de Bois-Préau, 92852 Rueil-Malmaison Cedex - France

e-mail: lars.ingolf.eide@hydro.com - marie.anheden@vattenfall.com - abanades@incar.csic.es - denis.clodic@enspm.fr -

mourad.younes@enspm.fr - alain.bill@power.alstom.com - p.h.m.feron@mep.tno.nl - alexandre.rojey@ifp.fr - fabrice.giroudière@ifp.fr

Résumé - Nouveaux procédés de capture - Six nouveaux procédés de capture très différents, en cours de développement en Europe, sont présentés dans cet article. Ils reposent sur des technologies de postcombustion, précombustion ou d'oxy-combustion. Tous sont très prometteurs du point de vue des performances techniques et/ou des coûts.

Abstract - Novel Capture Processes - Six widely differing, novel capture processes, currently under development in Europe are described. These processes cover the range of postcombustion, precombustion and denitrogenation and show favourable possibilities for integration with power plants. They can be regarded as potential break-throughs in technical performance and/or costs. 


\section{INTRODUCTION}

The capture process routes of postcombustion, precombustion and denitrogenation can be readily followed using existing separation processes and energy conversion processes. The technological challenge is in the scale-up, the use in power production and the integration of these processes and components. There is also scope for the use of novel capture technologies, which might lead to a break-through in performance or capture costs. This chapter describes a range of capture processes, which are currently under investigation in Europe and show considerable promise for performance improvement and cost reduction on the medium to long term. They include the advanced zero emission power concept, chemical looping combustion, high temperature adsorbents, antisublimation, membrane contactors and the coupling of a compact reformer with power generation.

\section{AZEP}

An efficient and cost-effective utilisation of the mixed conducting membrane (MCM) reactor is its integration into a conventional gas turbine based combined cycle (CCGT) to produce an Advanced Zero Emissions Power Plant (Sundvist et al., 2001). The AZEP concept is shown in Figure 1.

The combustion chamber in an ordinary gas turbine is here replaced by the MCM-reactor, which includes a combustion chamber, a "low" temperature heat exchanger, an MCM membrane and a high temperature heat exchanger. After compression in the ordinary gas turbine compressor the compressed air at about 18 bar is heated to $800-900^{\circ} \mathrm{C}$ in the "low" temperature heat exchanger before it enters the MCM membrane. The MCM section combines heat transfer and oxygen transport between the air stream and a sweep gas stream. Permeated oxygen is picked up by means of a circulating sweep gas containing mainly $\mathrm{CO}_{2}$ and $\mathrm{H}_{2} \mathrm{O}$. The concentration of oxygen in the circulating gas is about $10 \%$ at the inlet of the burner. Hot combusted gas then enters the high temperature heat exchanger co-current to the oxygen depleted air stream. This air stream will then be heated to about $1200^{\circ} \mathrm{C}$. The pressure difference over the membrane should be kept low (below 0.5 bar) to minimise any leakage. About $10 \%$ of the combusted gas is bled off at high pressure and heat is recovered by heating a smaller part of the compressed air. The hot oxygen depleted air is then expanded in the turbine to generate electrical power. Waste heat in both the oxygen-depleted air stream and the $\mathrm{CO}_{2}$ containing bleed gas stream is recovered in HRSG's by generating steam at various pressure levels and by preheating the fuel gas. The steam is utilised in a steam turbine for power generation. The $\mathrm{CO}_{2}$ containing bleed gas is further cooled to condense water. $\mathrm{CO}_{2}$ is recovered, compressed from about sweep gas pressure, liquefied and then pumped to its final pressure (100 bar). The concept allows $100 \% \mathrm{CO}_{2}$ capture and will in this case have less than $1 \mathrm{ppm} v / \mathrm{v} \mathrm{NOx}$ in the oxygen depleted outlet air.

Compared with a conventional CCGT the AZEP concept for a $50 \mathrm{MW}$ size gives 4.5 percentage points reduction in thermal efficiency with $100 \% \mathrm{CO}_{2}$ capture including pressurisation of $\mathrm{CO}_{2}$ to 100 bar. For a fair comparison with a CCGT with MEA scrubbing, that has a $\mathrm{CO}_{2}$ capture of $85 \%$, also a modified AZEP case with sequential combustion before the expander to raise the turbine inlet temperature has been calculated. In this case with a $\mathrm{CO}_{2}$ capture of $85 \%$ the

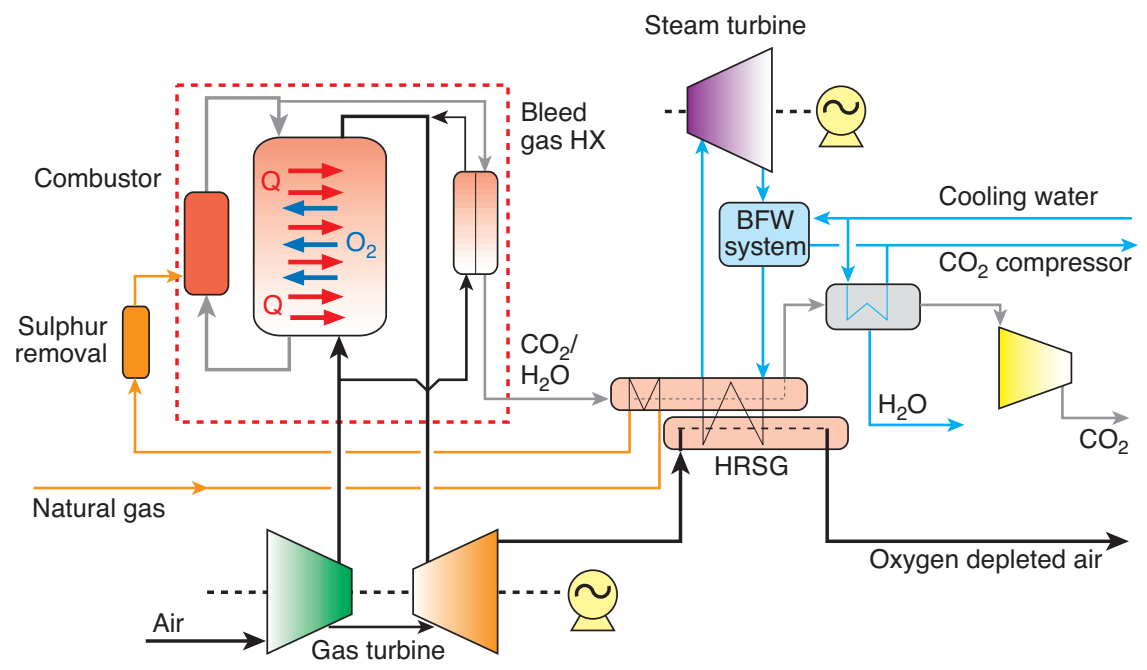

Figure 1

Advanced Zero Emission Power Plant (AZEP) concept. 
penalty in thermal efficiency is less than 3.0 percentage points compared to a standard CCGT. A 400 MW AZEP plant has a higher penalty in case of $100 \% \mathrm{CO}_{2}$ capture and it is recommended to use a sequential combustion before the expander to improve the thermal efficiency. In this case (85\% $\mathrm{CO}_{2}$ capture) the penalty in thermal efficiency, including pressurisation of $\mathrm{CO}_{2}$ to $100 \mathrm{bar}$, is 4.5 percentage points compared with e.g. a Siemens V94.3A CCGT plant. Recently the optimised AZEP concept was compared with a conventional CCGT with MEA scrubbing $\mathrm{CO}_{2}$ capture (Sundvist et al., 2004). The evaluation results showed that the penalty in thermal efficiency (LHV) was 4.5 percentage points for a AZEP $400 \mathrm{MW}$ case with $85 \% \mathrm{CO}_{2}$ capture compared with an efficiency penalty of 8.9 percentage points for a 400 MW CCGT with MEA scrubbing $\mathrm{CO}_{2}$ capture. The commercialisation of the technology is expected around 2010 (Simmonds et al., 2004).

\section{CHEMICAL LOOPING COMBUSTION}

In chemical-looping combustion (CLC) the combustion air and the fuel are never mixed. The system is composed of two reactors, an air and a fuel reactor (see Fig. 1). Normally the fuel is in a gaseous form and is introduced to the fuel reactor, which contains a metal oxide, $\mathrm{Me}_{\mathrm{x}} \mathrm{O}_{\mathrm{y}}$. The fuel and the metal oxide react according to:

$$
\begin{aligned}
(2 \mathrm{n}+\mathrm{m}) \mathrm{Me}_{\mathrm{x}} \mathrm{O}_{\mathrm{y}} & +\mathrm{C}_{\mathrm{n}} \mathrm{H}_{2 \mathrm{~m}} \\
& \rightarrow(2 \mathrm{n}+\mathrm{m}) \mathrm{Me}_{\mathrm{x}} \mathrm{O}_{\mathrm{y}-1}+\mathrm{mH}_{2} \mathrm{O}+\mathrm{nCO}_{2}
\end{aligned}
$$

The exit gas stream from the fuel reactor contains $\mathrm{CO}_{2}$ and $\mathrm{H}_{2} \mathrm{O}$, and a stream of $\mathrm{CO}_{2}$ is obtained when $\mathrm{H}_{2} \mathrm{O}$ is condensed. The reduced metal oxide, $\mathrm{Me}_{\mathrm{x}} \mathrm{O}_{\mathrm{y}-1}$, is transferred to the air reactor where it is oxidized, Reaction (2):

$$
\mathrm{Me}_{\mathrm{x}} \mathrm{O}_{\mathrm{y}-1}+1 / 2 \mathrm{O}_{2} \rightarrow \mathrm{Me}_{\mathrm{x}} \mathrm{O}_{\mathrm{y}}
$$

The air which oxidizes the metal oxide produces a flue gas containing only $\mathrm{N}_{2}$ and some unused $\mathrm{O}_{2}$. Depending upon the metal oxide used, Reaction (1) is often endothermic, while Reaction (2) is exothermic. The total amount of heat evolved from Reactions (1) and (2) is the same as for normal combustion, where the oxygen is in direct contact with the fuel. The advantage of chemical-looping combustion compared to normal combustion is that $\mathrm{CO}_{2}$ is not diluted with $\mathrm{N}_{2}$ but obtained in a separate stream without any energy needed for separation.

The reactors in Figure 2 could be designed in a variety of ways, but two interconnected fluidised beds have an advantage over alternative designs, because the process requires a good contact between gas and solids as well as a significant flow of solid material between the two reactors, (Lyngfelt et al., 2001). An example of a circulating system composed of two connected fluidised beds, a high velocity riser and a low velocity bubbling fluidised bed, is shown

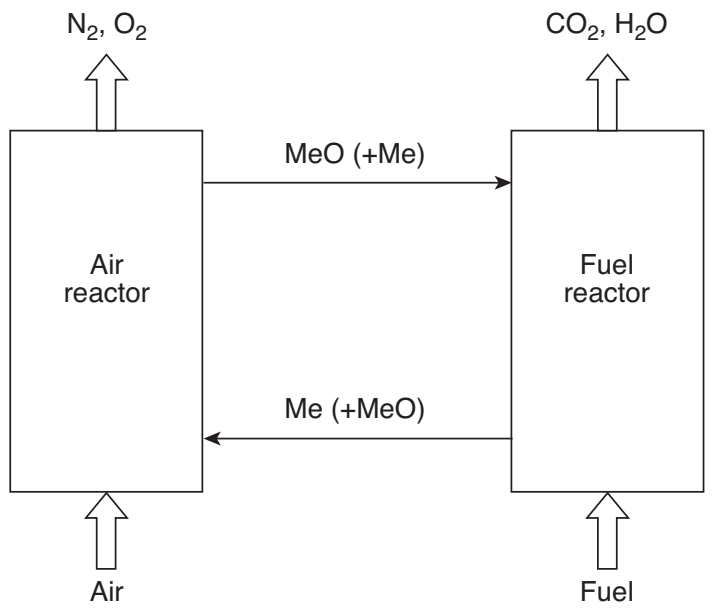

Figure 2

Chemical-looping combustion. $\mathrm{MeO} / \mathrm{Me}$ denote recirculated oxygen carrier solid material.

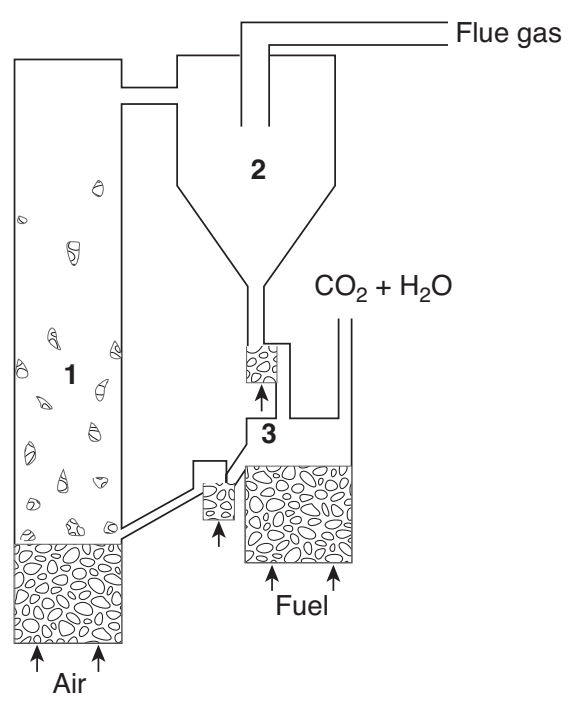

Figure 3

Layout of chemical-looping combustion process, with two interconnected fluidised beds. 1) air reactor, 2) cyclone, 3) fuel reactor.

in Figure 3. The bed material circulating between the two fluidised beds is the oxygen-carrier in the form of metal oxide particles. In the air reactor, or the riser, oxygen is transferred from the combustion air to the oxygen carrier. In the low velocity fluidised bed, or the fuel reactor, oxygen is transferred from the oxygen-carrier to the fuel.

The gas velocity in the riser provides the driving force for the circulation of particles between the two beds. Thus, the particles carried away from the riser are recovered by a cyclone and led to the fuel reactor. From the fuel reactor the particles are returned to the air reactor by means of gravity; 
the fuel reactor bed is at a higher level than the bed of the air reactor. The gas streams of the two reactor systems are separated by fluidised particle locks. Thus, the system is very similar to circulating fluidised bed combustion of solid fuels, a well established technology which has been used commercially for decades. After condensation of the water, the remaining gas, containing mostly $\mathrm{CO}_{2}$, is compressed and cooled in stages to yield liquid $\mathrm{CO}_{2}$. If there is remaining non-condensable gas from this stream containing unreacted combustibles, one option would be to recover this gas and recycle it to the fuel reactor. Another option is to add some oxygen to the gases leaving the fuel reactor.

A number of publications related to the development of oxygen-carrier particles have been issued by the research groups at Tokyo Institute of Technology, Chalmers University of Technology, Korea Institute of Energy Research, TDA Inc., CSIC-ICB in Zaragoza, National Institute for Resources and Environment in Japan and Politecnico di Milano. Also a number of papers investigate the possible thermal efficiencies of power processes involving chemical-looping combustion.

It should be pointed out that chemical-looping combustion addresses the capture by completely avoiding any gas separation. Thus, it is fundamentally different from the major paths for $\mathrm{CO}_{2}$ capture studied, which all involve a major step of gas separation: in postcombustion technologies $\mathrm{CO}_{2}$ is separated from flue gas, in oxy-fuel technologies oxygen is separated from air, and in precombustion technologies $\mathrm{CO}_{2}$ and $\mathrm{H}_{2}$ are separated. A comparable technology, however, is fuel cells where capture of $\mathrm{CO}_{2}$ can be accomplished without gas separation. Both chemical-looping combustion and fuel cells would best be categorized as unmixed combustion technologies.

Chemical-looping combustion is a fundamentally new technology for oxidizing ("burning") fuels in order to produce useful energy. The point to make is that combustion has a long start compared to chemical-looping combustion, and that adequate resources are needed to make this technology competitive.

A number of possible options for application of chemicallooping combustion for $\mathrm{CO}_{2}$ capture have been identified:

- combustion of gases such as natural gas, refinery gas and syngas from solid fuels;

- combustion of liquid fuels;

- direct combustion of solid fuels;

- partial oxidation/reforming processes for hydrogen or combined hydrogen/power production.

\section{State-of-Art}

In 2002, chemical-looping combustion was a paper concept with only a limited number oxides tested in laboratory. As such the process had never been demonstrated. Since then a rapid progress has been accomplished. In January 2002, the two-year EU-project "GRACE FP5" project started using fluid bed technology for chemical-looping combustion (Lyngfelt and Thunman, 2004; Lyngfelt et al., 2004). The goals were far-reaching and included:

- Manufacture, development and comprehensive testing of oxygen-carrier particles;

- Investigation of possible designs with respect to the fluidisation conditions to ensure proper conditions in the fluidised beds and a suitable recirculation flow of solids;

- Demonstration and evaluation of this new combustion technology in a $10 \mathrm{~kW}$ chemical-looping combustor;

- Design and costing of a chemical-looping CFB boiler for use at the Grangemouth refinery.

In the GRACE project more than 300 different particles were produced and investigated. The two best ones were produced in large quantities for testing in a $10 \mathrm{~kW}$ chemicallooping combustor.

The testing in the $10 \mathrm{~kW}$ unit showed that start-up, turndown and operation of the process were found to be easy. A total operation time of more than $100 \mathrm{~h}$ was reached with the same batch of particles, i.e. without adding fresh, unused material. During night-time and during start-up of operation the system was kept at high temperature and in circulation with electrical preheating. Thus, the actual time that the particles have been circulating in the system is close to $300 \mathrm{~h}$. The fuel used was natural gas, and a fuel conversion efficiency of $99.5 \%$ was accomplished, which is very close to the thermodynamic equilibrium of the $\mathrm{NiO} / \mathrm{Ni}$ system. It should be pointed out that there is no such thermodynamic restraint for the other metal oxide systems studied. There was no $\mathrm{CO}_{2}$ in the gas from the air reactor, indicating that a separation efficiency of $100 \%$ is possible. Furthermore, there was no leakage in the opposite direction, i.e. from the air to the fuel reactor, indicating that pure $\mathrm{CO}_{2}$ can be obtained in the process, except for nickel oxide for which there is a thermodynamic limitation. Neither decrease in reactivity nor particle strength was seen during the test period. The loss of fines was small and decreased steadily during the test period. In the end of the period the loss of fines, i.e. particles smaller than $45 \mu \mathrm{m}$, was $0.0023 \% / \mathrm{h}$. If this can be assumed to be a relevant measure of the steady-state attrition, it would correspond to a lifetime of the particles of $40000 \mathrm{~h}$. Assuming a lifetime of $4000 \mathrm{~h}$, the estimated cost for particles will be low, in the order of $1 € / t \mathrm{CO}_{2}$ captured.

A technical evaluation showed that the process uses technology very similar to circulating fluidised-bed combustion. Thus, a chemical-looping boiler can be built with adaptation of well-known technology. A preliminary costing has been performed for a $200 \mathrm{MW}_{\text {th }}$ chemical-looping combustion boiler for use at $B P$ 's Grangemouth refinery, indicating that CLC should feature strongly among the best options for reducing the cost of $\mathrm{CO}_{2}$ capture.

A $50 \mathrm{~kW}$ chemical-looping combustor has also been designed at Korea Institute of Energy Research and tests in 
this verify that there are virtually no NOx emissions from this system (Ryu et al., 2004).

\section{$3 \mathrm{CO}_{2}$ SEPARATION AT HIGH TEMPERATURES}

A number of power plant concepts are being proposed to produce $\mathrm{H}_{2}$, electricity or other decarbonised products by integrating in the fuel conversion route a separation of $\mathrm{CO}_{2}$ at high temperatures, based on the (dry) carbonation reaction of a metal oxide with $\mathrm{CO}_{2}$ :

$$
\mathrm{MeO}(\mathrm{s})+\mathrm{CO}_{2}(\mathrm{~g}) \leftrightarrow \mathrm{MeCO}_{3}(\mathrm{~s})
$$

The calcination of the carbonate regenerates the sorbent and produces a concentrated stream of $\mathrm{CO}_{2}$ suitable for disposal. The separation of $\mathrm{CO}_{2}$ at high temperatures is intrinsically associated to lower energy penalties in the separation step, because the heat required to regenerate the sorbent is recovered at sufficiently high temperatures during the carbonation reaction. In precombustion systems incorporating this concept the carbonation reaction can be integrated (in the same reactor) with another key reaction step in the process (gasification of the solid fuel and/or steam reforming of the fuel gas) increasing the yield of $\mathrm{H}_{2}$ by removing the $\mathrm{CO}_{2}$ from the water-gas shift equilibrium. This approach falls in the category of sorption (or absorption) enhance reforming processes because they allow better $\mathrm{H}_{2}$ purity beyond the equilibrium limits of the shift reaction at a given temperature. Calcium and lithium are the main metals being considered for the carbonation/calcinations cycle represented in Equation (3) and their associated processes are reviewed in the next paragraphs. There is a process being developed by Air Products (Hufton et al., 1999) making use of mixtures of potassium carbonate promoted hydrotalcites and a commercial SMR catalyst. The sorbent has a stable $\mathrm{CO}_{2}$ capture capacity of $0.45 \mathrm{~mol} / \mathrm{kg}$ (just about $1 \%$ weight) and the system operates following the principles of PSA. Since there is no much more information publicly available, this is not further discussed in this work.

The use of lithium containing oxides $\left(\mathrm{Li}_{2} \mathrm{O}\right.$ in $\mathrm{Li}_{2} \mathrm{ZrO}_{3}$ or $\mathrm{Li}_{4} \mathrm{SiO}_{4}$ ) to form $\mathrm{Li}_{2} \mathrm{CO}_{3}$ in a carbonation-calcination cycle, was first investigated in Japan (Nakagawa et al., 1998; Kato et al., 2002). The reported performance of these sorbents is very good, with very high reactivity in a wide range of temperatures below $700^{\circ} \mathrm{C}$, rapid regeneration at slightly higher temperatures and durability in repeated captureregeneration cycles. However, since lithium is an intrinsically expensive material, the performance may have to be demonstrated in the scale of many thousands of cycles (Abanades et al., 2004) to be competitive with commercial systems.

For the case of $\mathrm{CaO} / \mathrm{CaCO}_{3}$ systems, the background for the basic separation processes goes back to 1867 , when DuMotay and Marechal first patented the use of lime to aid the gasification of carbon by steam. One century later, this separation principle was proven in the Acceptor Gasification Process (Curran et al., 1967) in successful pilot tests involving two interconnected fluidised beds working at high pressure $(2 \mathrm{MPa})$ and temperatures of $815^{\circ} \mathrm{C}$ in the fluidised bed gasifier and $1060^{\circ} \mathrm{C}$ in the calciner. Note that the scale of these pilot test (40 $\mathrm{t}$ of coal/day) compares favourably with the level of testing of some leading $\mathrm{CO}_{2}$ capture options today. However, in these early processes, the release of all the $\mathrm{CO}_{2}$ produced in the calciner was not an issue, because the objective was to produce a higher quality gas from the gasifier. Hence, calcination was achieved by combustion of part of the fuel with air. The need to obtain a purified stream of $\mathrm{CO}_{2}$ from the calciner is new and related to the concept of $\mathrm{CO}_{2}$ capture and storage. Hirama et al. (1994) first proposed a cycle for combustion applications, involving the regeneration of the sorbent in a oxygen-fired fluidised bed combustor-calciner. Silaban and Harrison (1995) first outlined the use of the reversible carbonation/calcination reaction as the base of a $\mathrm{CO}_{2}$ capture system to produce hydrogen. A range of systems are being developed following the combustion or gasification routes. Their detail definition depends on the technology adopted for gasification, carbonation and calcination reactors, hydrogen utilisation route, and storage option for $\mathrm{CO}_{2}$. They are briefly outlined below.

For the precombustion route, one of the concepts was proposed at the Los Alamos National Laboratory (United States) and is currently under development as the Zero Emission Coal (ZEC) process (Ziock et al., 2002). It involves a hydrogasification step of the fuel and a reformer with in situ capture of $\mathrm{CO}_{2}$ by $\mathrm{CaO}$. The full system includes a robust fuel cell and a technology for mineral carbonation that does not yet exist. Another example is the HyPrRing process (Lin et al., 2002) that is being developed by the Center for Coal Utilization of Japan. It integrates gasification, reforming and in situ $\mathrm{CO}_{2}$ capture in a single reactor at pressures above $12 \mathrm{MPa}$ and temperature above $650^{\circ} \mathrm{C}$. Projects in Norway, using natural gas (Areklett and Nygaard, 2002) and in the European Union using brown coal (Berger et al., 2004) are also underway. Finally, General Electric (Rizeq, 2002) is developing an innovative system involving the capture of $\mathrm{CO}_{2}$ in the gasification reactor by a high temperature sorbent and the calcination in a different reactor by burning part of the fuel with an oxygen carrier.

Following the postcombustion route, an ECSC project has been investigating several concepts incorporating a lime carbonation-calcination cycle to coal combustion systems, focusing on the investigation of the decay in sorbent performance, overall system design issues and the pilot testing of main carbonation options (Abanades and Alvarez, 2003; Abanades et al., 2004). The common feature of these concepts is the transfer of part of the energy required for calcination from the high temperature combustor chamber 
TABLE 1

Frosting temperatures as a function of the $\mathrm{CO}_{2}$ concentration in the flue gases

\begin{tabular}{l|c|c|c|c|c|c|c|c}
\hline $\begin{array}{l}\text { Concentration } \\
(\mathbf{\%} / \mathbf{v})\end{array}$ & $\mathbf{1 0 0}$ & $\mathbf{1 5}$ & $\mathbf{1 0}$ & $\mathbf{5}$ & $\mathbf{2}$ & $\mathbf{1}$ & $\mathbf{0 . 1}$ & $\mathbf{0 . 0 0 2}$ \\
\hline $\begin{array}{l}\text { Frosting temperature } \\
\left({ }^{\circ} \mathrm{C}\right)\end{array}$ & -78.5 & -99.3 & -103.1 & -109.3 & -116.7 & -121.9 & -136.7 & -155.8 \\
\hline
\end{tabular}

and the use of lower calcinations temperatures by using steam and/or industrial vacuum in the calciner. Wang et al. (2004) have reported on similar systems operating at high temperatures and pressures. Alstom is developing in the US (Marion et al., 2004) concepts that involve the integration of the carbonation-calcination cycle in a CFB or in their Circulating Moving Bed reactor. A detail cost comparison of several emerging options for $\mathrm{CO}_{2}$ capture gives these options a very attractive positions respect to other advanced and existing systems (Nsakala et al., 2004).

A common problem for all systems using $\mathrm{CaO} / \mathrm{CaCO}_{3}$ as a regenerable sorbent is that particles of natural limestones and dolomites, loose activity rapidly as the number of carbonation-calcination cycles increases. As a consequence, very large make up flows for sorbent (in the order of the mass flow of fuel entering the plant) are required to maintain the activity of the capture-regeneration loop. A range of methods to enhance the activity of Ca-based $\mathrm{CO}_{2}$ sorbents are being pursued by several $\mathrm{R} \& \mathrm{D}$ groups around the world or to manufacture more stable synthetic sorbents based on $\mathrm{CaO}$. It is not yet clear if these methods will translate into large reduction of the sorbent make up costs. This is because limestone has a very low unit price and deactivated sorbent could find application in the cement industry gaining additional $\mathrm{CO}_{2}$ credits for the system (the feedstock for the cement plant would be $\mathrm{CaO}$ instead of $\mathrm{CaCO}_{3}$ ). In a recent cost/performance comparison of different $\mathrm{CO}_{2}$ capture systems following the scheme of a sorption-desorption system, it has been shown (Abanades et al., 2004) that the make up flow of limestone is not a real economic barrier for these cycles because (calcined) crushed limestone is, by far, the cheapest possible $\mathrm{CO}_{2}$ regenerable sorbent.

\section{ANTI-SUBLIMATION}

A new $\mathrm{CO}_{2}$ capture process has been developed at the Center for Energy and Processes and two patents have been filed [Clo01; Clo2]. The $\mathrm{CO}_{2}$ is captured by anti-sublimation on a low temperature surface at atmospheric pressure. This process can be implemented as a post-treatment system on current energy production system but it can be also used for high $\mathrm{CO}_{2}$ concentration process gases.

The temperature of sublimation of a substance depends on its partial pressure in the gas mixture. The $\mathrm{CO}_{2}$ triple point is at $520 \mathrm{kPa},-56.6^{\circ} \mathrm{C}$, which means that for partial pressures lower than $520 \mathrm{kPa}$, the $\mathrm{CO}_{2}$ goes directly from the gas phase to the solid phase (anti-sublimation).

Table 1 presents the sublimation temperatures of $\mathrm{CO}_{2}$ for different concentrations, and so for different partial pressures of $\mathrm{CO}_{2}$ in the flue gases.

For instance, the capture of $90 \%$ of $\mathrm{CO}_{2}$ in flue gases with an initial $\mathrm{CO}_{2}$ content of $10 \% \mathrm{v} / \mathrm{v}$ is performed between $-103.1^{\circ} \mathrm{C}$ and $-121.9^{\circ} \mathrm{C}$.

The diagram of the $\mathrm{CO}_{2}$ capture cycle is presented on the $\mathrm{CO}_{2}$ T-s diagram in Figure 4.

The energy recovery during defrosting from the $\mathrm{CO}_{2}$ sublimation and melting (evolution $\mathrm{CDE}$ on Figure 1) leads to a significant energy saving of the capture process. This recovery process is realized by swinging from one evaporator to the other. The refrigerant blend at "high temperature" $\left(-45^{\circ} \mathrm{C}\right)$ circulating in the tubes recovers heat while defrosting the $\mathrm{CO}_{2}$ laid down on the fins.

The overall scheme of the $\mathrm{CO}_{2}$ capture system on flue gases is presented in Figure 5.

The Flue Gases (FG) are first cooled to near the ambient temperature in the Cooling Stage 1 (CS1) and a first quantity of water is captured by condensation. CS2HT and CSS2LT are refrigeration systems used to cool the $\mathrm{FG}$ to near $0^{\circ} \mathrm{C}$ and capture additional water by condensation.

The FG enter a first FG/FG heat exchanger where they are cooled to near $-15^{\circ} \mathrm{C}$ frosting more water from the $\mathrm{FG}$ stream before being cooled at a lower temperature $\left(-40^{\circ} \mathrm{C}\right)$ by the refrigeration system CS3 to capture the remaining water by frosting. Whenever there is water frosting, a defrosting strategy is applied in order to allow a continuous operation of the system. The FG enter then a second FG/FG heat exchanger where they will be cooled to near $-100^{\circ} \mathrm{C}$ before going into the $\mathrm{CO}_{2}$ capture Low Temperature Frosting Evaporators (LTFE). The LTFE are operated successively in order to perform a continuous $\mathrm{CO}_{2}$ capture process.

Once the $\mathrm{CO}_{2}$ is frosted on the frosting LTFE, a defrosting cycle is performed on the other one. The defrosting evaporator enclosure is closed during the sublimation of $\mathrm{CO}_{2}$ resulting in a pressure rise inside the LTFE enclosure. Once the pressure reaches the triple point pressure, the remaining solid $\mathrm{CO}_{2}$ melts and the $\mathrm{CO}_{2}$ recovery system is run in order to recover the liquid and gaseous $\mathrm{CO}_{2}$ from the LTFE enclosure to store it in an intermediate pressure $\mathrm{CO}_{2}$ tank (around $600 \mathrm{kPa}$ ) before it can be compressed to $15 \mathrm{MPa}$ for transportation or sequestration purposes. The compression is 


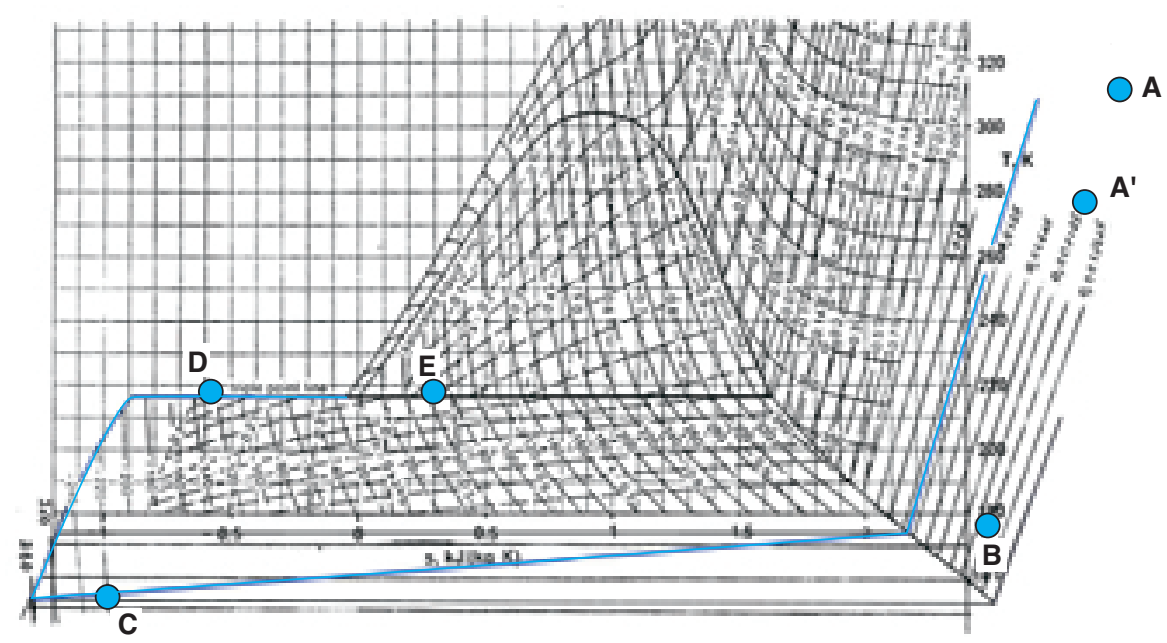

Figure 4

Representation of the cycle in the $\mathrm{CO}_{2} \mathrm{~T}$-s diagram. AA' represents the gas cooling town near $0^{\circ} \mathrm{C}$ for water capture by condensation; $\mathrm{A}^{\prime} \mathrm{B}$ represents the gas cooling town to the $\mathrm{CO}_{2}$ frosting temperature; $\mathrm{BC}$ represents the $\mathrm{CO}_{2}$ frosting and thus its capture; $\mathrm{CD}$ represents the $\mathrm{CO}_{2}$ sublimation and its temperature rise; $\mathrm{DE}$ represents the fusion of the solid $\mathrm{CO}_{2} ; \mathrm{CDE}$ represents the recovered energy from the $\mathrm{CO}_{2}$ coolness.

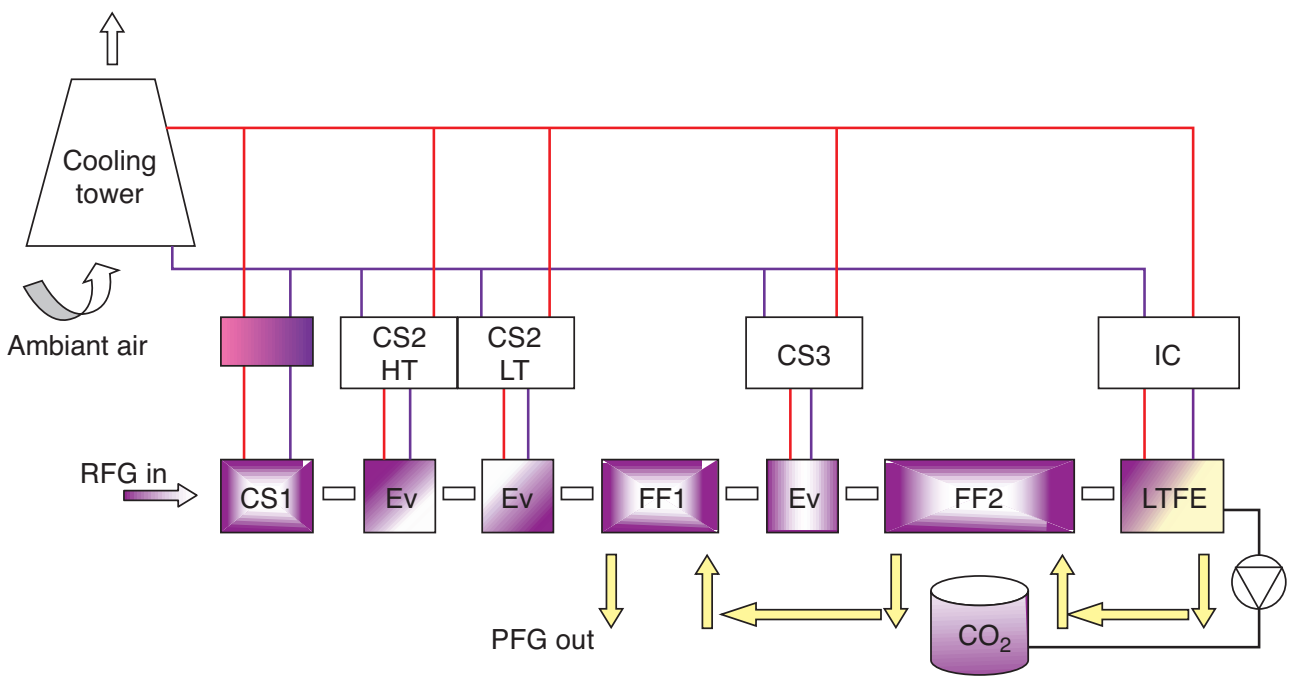

\begin{tabular}{|c|c|}
\hline PFG: & $\begin{array}{l}\mathrm{CO}_{2} \text { poor } \\
\text { flue gases }\end{array}$ \\
\hline RFG: & $\begin{array}{l}\mathrm{CO}_{2} \text { rich } \\
\text { flue gases }\end{array}$ \\
\hline SCi: & $\begin{array}{l}\text { cooling } \\
\text { stage i }\end{array}$ \\
\hline IC: & $\begin{array}{l}\text { integrated } \\
\text { cascade }\end{array}$ \\
\hline Ev: & evaporator \\
\hline HT: & $\begin{array}{l}\text { high } \\
\text { temperature }\end{array}$ \\
\hline LT: & $\begin{array}{l}\text { low } \\
\text { temperature }\end{array}$ \\
\hline FFi: & $\begin{array}{l}\mathrm{FG} / \mathrm{FG} \\
\text { heat exchanger }\end{array}$ \\
\hline & $\begin{array}{l}\text { low T. } \\
\text { frosting Ev }\end{array}$ \\
\hline
\end{tabular}

Figure 5

Representation of the $\mathrm{CO}_{2}$ capture system.

done in liquid phase leading to a low energy consumption for this compression process.

A key component of the process is the low temperature refrigeration system: an integrated cascade operated by a single compression stage with a blend of low GWP refrigerants.

A 4-stage architecture with a mix of vapour flow rates at the low-pressure side, called MLPS (Mix Low Pressure Streams), architecture has been designed (Fig. 6).
This architecture can reach a $60 \%$ efficiency relative to the ideal Carnot cycle if the successive expansions are performed by expanders.

A study of the overall $\mathrm{CO}_{2}$ capture system has been performed by the laboratory and the components of the different sub-systems have been designed, realized or purchased; a test bench has been built in order to demonstrate the $\mathrm{CO}_{2}$ capture principle and evaluate the performances of the system. 


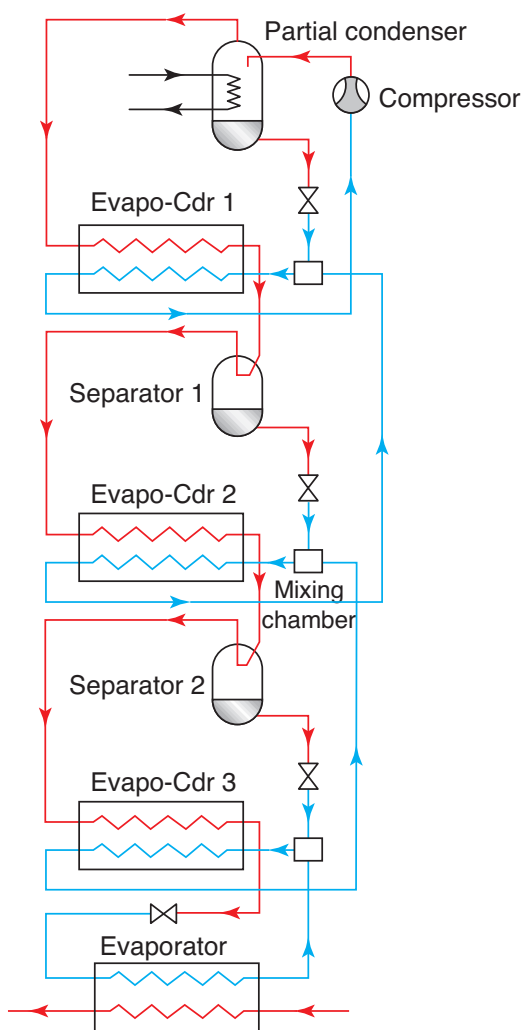

Figure 6

MLPS integrated cascade.

The system operated as expected. Figure 7 shows the $\mathrm{CO}_{2}$ frosted on the LTFE fins while Figure 8 shows the liquid $\mathrm{CO}_{2}$ recovered in the LTFE enclosure.

Figure 9 shows the $\mathrm{CO}_{2}$ concentration evolution across the $\mathrm{CO}_{2}$ capture system for a $\mathrm{CO}_{2}$ inlet concentration of about $13 \% \mathrm{CO}_{2}$ in volume. The test is performed for $90 \% \mathrm{CO}_{2}$ capture efficiency.

Several tests for different $\mathrm{CO}_{2}$ inlet concentrations have been performed (from 1 to $23 \% \mathrm{CO}_{2} \mathrm{v} / \mathrm{v}$ ); they show that a $\mathrm{CO}_{2}$ capture efficiency of $90 \%$ could be performed for all this ranges of inlet concentrations.

The main energy requirements are at the $\mathrm{CO}_{2}$ capture level. The energy requirements depend on the $\mathrm{CO}_{2}$ concentration in the $\mathrm{FG}$ and on the $\mathrm{CO}_{2}$ capture efficiency.

Typically, the energy penalty for this $\mathrm{CO}_{2}$ capture method is about (650 to $1250 \mathrm{~kJ} / \mathrm{kg} \mathrm{CO} \mathrm{CO}_{2}$ ) 4 to $8 \%$ points for a pulverized coal boiler depending on the refrigeration cycles efficiencies or coefficient of performance (respectively $80 \%$ and $50 \%$ efficiencies relative to the ideal Carnot cycle). The incremental cost of electricity would range between 0.57 and $0.88 €$ cents $/ \mathrm{kWhe}$ while the $\mathrm{CO}_{2}$ mitigation cost would range between 10 and $16 € / \mathrm{t}$ of $\mathrm{CO}_{2}$ avoided (results given for $90 \% \mathrm{CO}_{2}$ capture efficiency, $1.6 € / \mathrm{GJ}$ coal, 30 y lifetime at $67 \%$ duty).

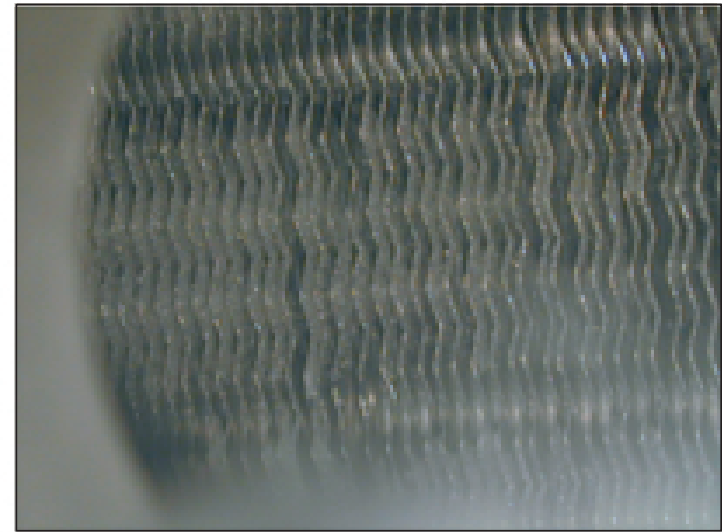

Figure 7

Frosted $\mathrm{CO}_{2}$ on the evaporator fins.

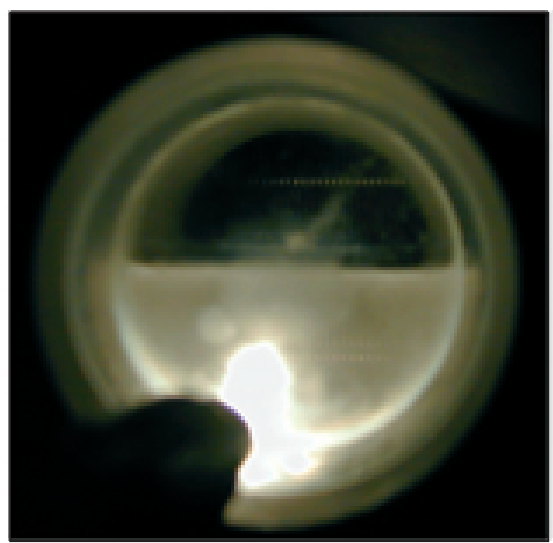

Figure 8

Liquid $\mathrm{CO}_{2}$ after defrosting.

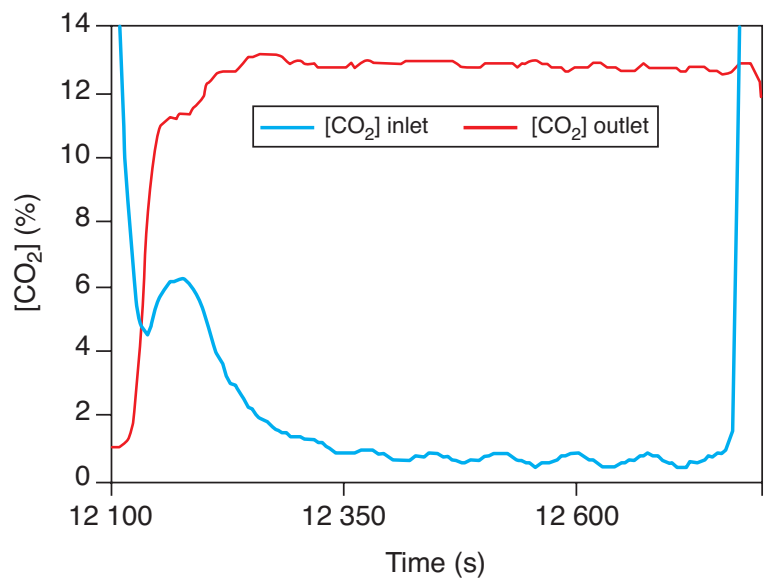

Figure 9

Test for a $\mathrm{CO}_{2}$ concentration of $13 \% \mathrm{v} / \mathrm{v}$. 
For the gas fired power plants, the energy penalty is rather in the range of ( 820 to $1520 \mathrm{~kJ} / \mathrm{kg} \mathrm{CO}$ ) 6 to $11.3 \%$ points (for respectively 80 and $50 \%$ efficiencies relative to the ideal Carnot cycle). The incremental cost of electricity would range between 0.7 and $1 € \mathrm{cent} / \mathrm{kWhe}$ while the mitigation cost would range between 17 and $24 € / t$ of $\mathrm{CO}_{2}$ avoided (results given for $90 \% \mathrm{CO}_{2}$ capture efficiency, $2.85 € / \mathrm{GJ}$ natural gas, 25 y lifetime at $67 \%$ duty).

\section{MEMBRANE CONTACTORS}

Membrane processes are used commercially for $\mathrm{CO}_{2}$ removal from natural gas at high pressure and at high $\mathrm{CO}_{2}$ concentration. In flue gases, the low $\mathrm{CO}_{2}$ partial pressure difference provides a low driving force for gas separation. The removal of carbon dioxide using commercially available polymeric gas separation membranes results in higher energy penalties on the generating efficiency compared to a standard chemical absorption process (Herzog et al., 1991; Van der Sluijs et al., 1992; Feron, 1994). Also, the maximum percentage of $\mathrm{CO}_{2}$ removed is lower than for a standard chemical absorption processes. Improvements can be made if more selective membranes become available. The membrane option currently receiving the most attention is a hybrid membrane-absorbent (or solvent) system where the membrane is used as a contactor between a gas and a liquid stream (membrane gas absorption).

The principle of membrane gas absorption is shown in Figure 10.

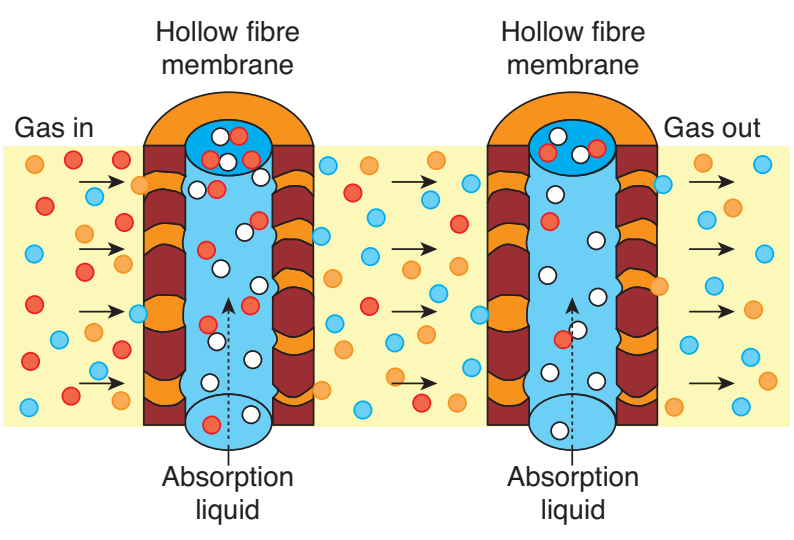

Figure 10

Principle of membrane gas absorption.

The essential element in a membrane absorber is a porous, water repellent, polymeric membrane. The gas phase remains separated from the liquid absorbent as a result of the hydrophobicity of the membrane. A flue gas stream is fed along one side of the membrane. The components to be removed from the gas stream will diffuse through the gas filled pores of the membrane. On the other side of the membrane they will be absorbed into the absorption liquid. The use of a membrane absorber leads to the following advantages:

- Gas and liquid flow are independent resulting in avoidance of problems encountered in packed/tray columns such as flooding, foaming, channelling and entrainment.

- No need to have a wash section after the absorber to recover absorption liquid which is carried over.

- Operation at thermodynamically optimal conditions, not dictated by the hydrodynamic conditions of the contacting equipment.

- Operation not influenced by the orientation of the absorber which is important in offshore applications and zerogravity applications.

- Equipment will be compact through the use of hollow fibre membrane.

These advantages are expected to result in sizeable cost reductions for the absorber, which is the most expensive equipment in postcombustion $\mathrm{CO}_{2}$ capture using solvent technology.

The choice of a suitable combination of absorption liquid and membrane is very important.

The hydrophobicity and pore characteristics of the membrane material should be such that the pores remain gasfilled at an excess pressure of preferably more than 1 bar on the liquid side. Commercially available porous polyolefin membranes appear not to be suitable for operation with the usual absorption liquids, i.e. aqueous solutions of ethanolamines. In the course of time such liquids will seep through these membranes as a result of the low surface tension of the organic liquid/water mixtures. This can be resolved by the utilisation of expensive PTFE membranes (Falk-Pedersen, et al., 1998). An alternative solution to this is the use of an absorption liquid of surface tension similar to water. TNO has developed the membrane gas absorption process for acid gas removal based on a patented working method using dedicated absorption liquids (CORAL) based on mixtures of salts and amino-acids and polyolefin membranes (Feron and Jansen, 2002). This paves the way towards the use of inexpensive polyolefin membranes, developed for e.g. medical applications (artificial lungs), which is believed to be essential for economic success of membrane gas absorption. The use of salt solutions also has the advantage that the vapour pressure of the active components is zero and the solvent is not lost through evaporation.

The overall flow sheet of a membrane gas absorption process, shown in Section 2, is similar to a conventional absorption process flow sheet. In brief: the flue gas containing carbon dioxide is counter-currently brought into contact with the absorption liquid in the membrane absorber. The rich absorption liquid is fed via a heat exchanger to the regenerator where carbon dioxide is released at high temperature. 
The membrane absorber design cannot be based on conventional membrane module designs. These designs have historically been based on the use of hollow fibre membranes for filtration duties with oil-defined flow conditions on the shell side of the membrane. When membranes are used for contacting duties, as is the case for membrane gas absorption, it is necessary that flow conditions be well defined on either side of the membrane to achieve good mass transfer. Furthermore it is essential that, given the large volume flows of flue gas streams, the module design is easy to scale up. This is crucial to the commercial success of membrane gas absorption.

Theoretically based performance comparisons between packed columns and membrane absorbers have shown that a membrane absorber can lead to a ten-fold reduction in absorber size for $\mathrm{CO}_{2}$-removal from flue gas Feron and Jansen (1995), illustrating the potential of membrane gas absorption.

\section{HYGENSYS}

The HyGenSys process concerns the production of hydrogen and power, with $\mathrm{CO}_{2}$ capture at the pre-combustion stage. It includes a compact SMR reactor based on a new heating concept. The new process arrangement leads to a cogeneration of hydrogen and electrical power and can incorporate either a current or advanced $\mathrm{CO}_{2}$ capture step. In both cases, as a result of a high energy integration, the HyGenSys process represents an attractive option for hydrogen and power production with $\mathrm{CO}_{2}$ capture.

Within the current design of SMR reactors, the efficiency of the radiant section is low (about 50\%) and the global energy efficiency is mainly linked to the on-site utilisation of steam produced in the heat recovery convection section. As low pressure steam is difficult to exploit, for a wide deployment of hydrogen production, an energy efficiency increase of the reaction section is needed. The HyGenSys process is expected to meet this requirement due to the use of a high efficiency compact reformer coupled with power generation (Fig. 11).

In the first SMR reactor, the endothermic steam-reforming reaction takes place and methane reacts with water, by forming a hydrogen/CO mixture. The SMR reactor is heated by hot pressurised gases, supplied by a jet engine gas generator. The jet engine gas generator is fed with air and methane or hydrogen if a zero $\mathrm{CO}_{2}$ emission level is required. The hot flue gases generated by the gas turbine can be used directly for heating the reactor or expanded in a turbine from 25 to 4 bar to compress combustion air. In both cases the hot gases are used to heat up the compact SMR reactor by circulating in the shell side of the reactor/exchanger. As the hot gases are under pressure, the volumetric flow-rate is reduced and it is also possible to relax pressure loss constraints and circulate the hot gases at a higher velocity, resulting in a compact reactor design. At the exit of the reactor, hot gases are expanded to generate power. After exiting the heat/exchanger reactor, the hot synthesis gas is partially cooled by indirect heat-exchange and then cooled to the optimum shift-conversion inlet temperature by quenching with boiler feed water. It is then introduced in the shiftconversion reactor, where the exothermic shift-conversion takes place and produces additional hydrogen by reacting $\mathrm{CO}$ with water.

After shift-conversion step, the synthesis gas is sent to a $\mathrm{CO}_{2}$ separation step, according to the scheme in Figure 12b.

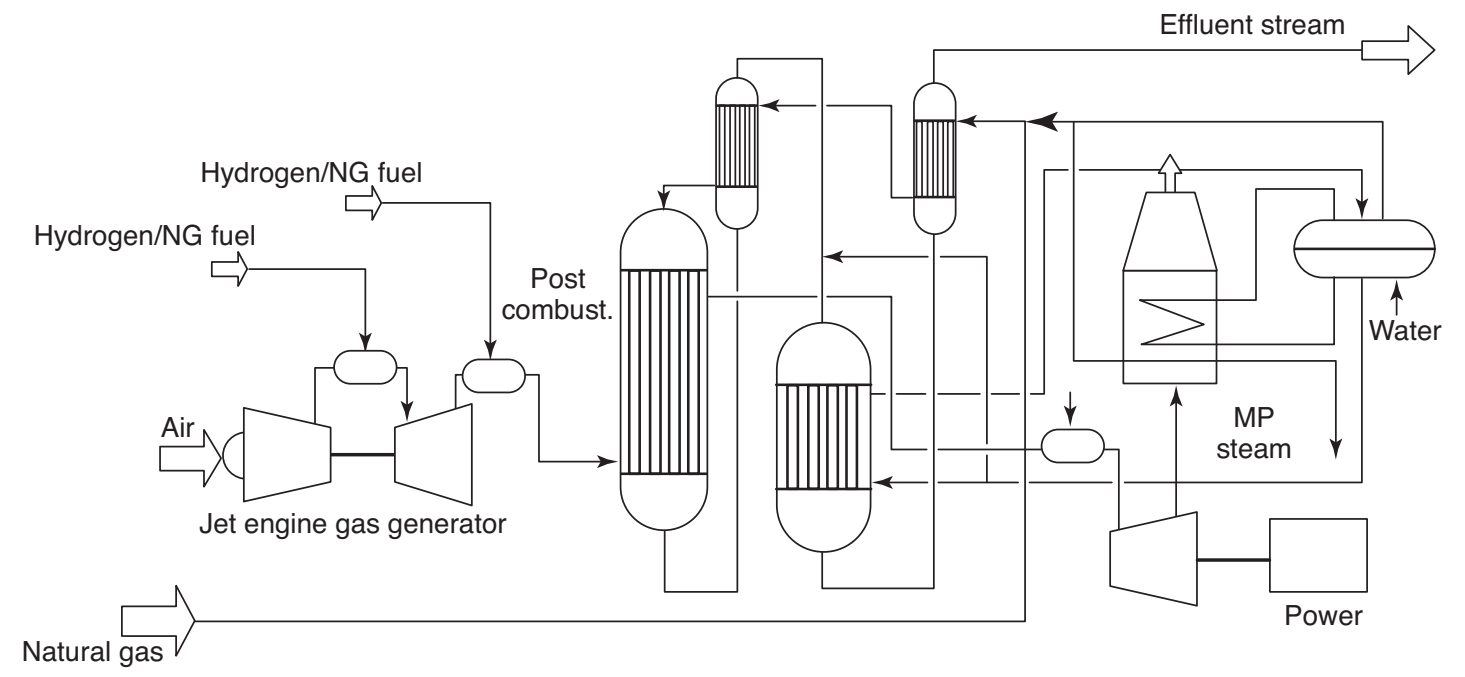

Figure 11

HyGenSys basic process scheme. 


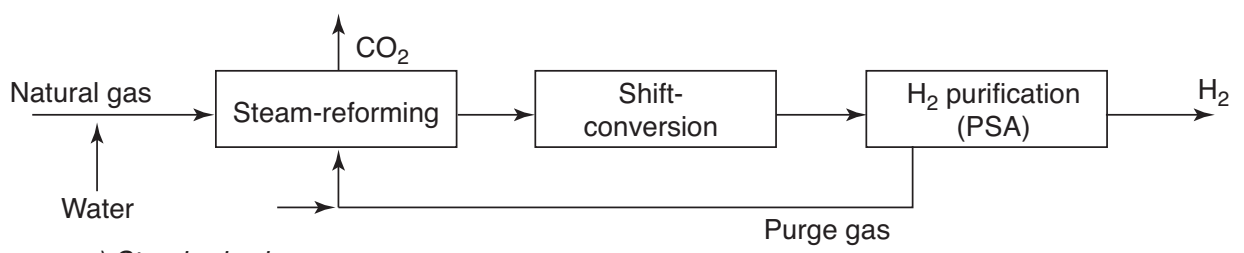

a) Standard scheme

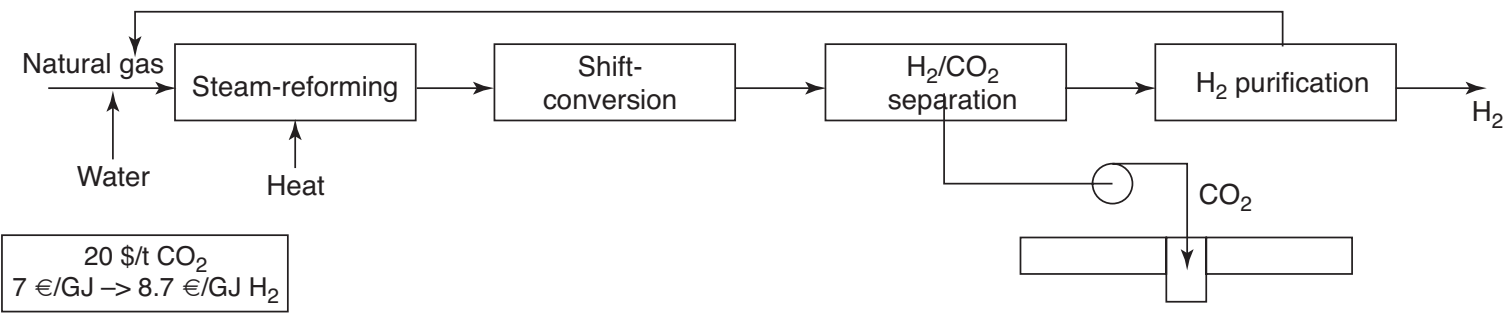

b) Hydrogen production with $\mathrm{CO}_{2}$ capture and sequestration

Figure 12

$\mathrm{CO}_{2}$ capture.

Carbon dioxide can be separated from hydrogen by using different solvent wash processes. A process using a refrigerated solvent, such as the Ifpexol process is very well adapted. After recovery, carbon dioxide can be compressed or pumped in liquid phase and injected underground for permanent storage. After the solvent wash, the hydrogen stream still contains unconverted light hydrocarbons and is sent to a final purification step by fixed-bed adsorption.

Light hydrocarbons which are separated can be mixed with a feed gas fraction and used for heating the SMR reactor. If a zero $\mathrm{CO}_{2}$ emission level is required, a hydrogen stream can be used. In such a case light hydrocarbons separated from hydrogen during the final purification step are either exported or recycled.

Nowadays, there are several options for meeting the growing hydrogen needs. The most common hydrogen production technology is steam reforming which can handle a variety of feedstock including natural gas, LPG, naphtha. Autothermal reforming or partial oxidation reactors could also be used but these two processes lead to higher $\mathrm{CO}_{2}$ emissions due to the energy consumption of the air separation unit for oxygen production. The hydrogen over $\mathrm{CO}$ ratio in the synthesis gas is also lower and therefore less favourable.

Steam methane reformers (SMR) are based on very mature technologies and can be provided by a large number of engineering companies such as Foster Wheeler Corp., Haldor Topsoe AS, Technip, Lurgi, Uhde. However SMR reactors remain large and expensive to construct mainly due to the large fire box and upper convection section. The development of compact steam reformers appears as a most promising pathway for reducing the investment cost, limiting on-site building time and increasing opportunities for process integration with downstream process units.

If hydrogen production is to be rapidly expanded in the near future, the energy efficiency of SMR units will need to be increased. In the HyGenSys process, the enthalpy of the heating stream is fully recovered by using a gas turbine cycle, resulting in a high overall efficiency.

Therefore, the HyGenSys process is expected to produce hydrogen with $\mathrm{CO}_{2}$ capture at quite a competitive cost, below $9 € / \mathrm{GJ}$, corresponding to a low $\mathrm{CO}_{2}$ capture cost in the range of 15 to $20 € /$ t.

\section{REFERENCES}

Abanades, J.C. and Alvarez, D. (2003) The Conversion Limits in the Reaction of $\mathrm{CO}_{2}$ with Lime. Energy and Fuels, 17, 2, 308315 .

Abanades, J.C., Anthony, E.J., Alvarez, D., Lu, D.Y. and Salvador, C. (2004) Capture of $\mathrm{CO}_{2}$ from Combustion Gases in a Fluidized Bed of CaO. AIChE J, 50, 7, 1614-1622.

Abanades, J.C., Rubin, E.S. and Anthony, E.J. (2004) Sorbent Cost and Performance in $\mathrm{CO}_{2}$ Capture Systems. Ind. Eng. Chem. Res., 43, 3462-3466.

Areklett, I. and Nygaard, L.P. (2002) Future Energy Plants, Greenhouse Issues, IEA Greenhouse Gas R\&D Programme, 59.

Berger, R et al. (2003) Innovative in situ $\mathrm{CO}_{2}$ Capture Technology for Solid Fuel Gasification. Contract SES6-CT-2003-502743. www.eu-projects.de.

Curran, G.P., Fink, C.E. and Gorin, E. (1967) Carbon DioxideAcceptor Gasification Process. Studies of Acceptor Properties. Adv. Chem. Ser., 69, 141.

Falk-Pedersen, O., Dannström, H., Grønvold, M., Stuksrud, D.B., and Rønning, O. (1998) Gas Treatment Using Membrane Gas/ Liquid Contractors, Greenhouse Gas Control Technologies. Riemer, P., Eliasson, B. and Wokaun, A. (eds.), Elsevier Science Ltd., Kidlington, United Kingdom, 115-120.

Feron, P.H.M. (1994) Membranes for Carbon Dioxide Recovery from Power Plants. In: Carbon Dioxide Chemistry, Environmental 
Issues, Paul, J. and Pradier, C.M. (eds.), The Royal Society of Chemistry, Cambridge, United Kingdom, 236-249.

Feron, P.H.M., and Jansen, A.E. (1995) Capture of Carbon Dioxide Using Membrane Gas Absorption and Reuse in the Horticultural Industry. Energy Convers. Mgmt., 36, 6-9, 411-414.

Feron, P.H.M and Jansen, A.E. (2002) $\mathrm{CO}_{2}$ Separation with Polyolefin Membrane Contactors and Dedicated Absorption Liquids. Performances and Prospects, Separation and Purification Technology, 27, 3, 231-242.

Herzog, H., Golomb, D. and Zemba, S. (1991) Feasibility, Modeling and Economics of Sequestering Power Plant $\mathrm{CO}_{2}$ Emissions in the Deep Ocean. Environmental Progress, 10, 1, 64-74.

Hirama, T., Hosoda H., Kitano, K. and Shimizu T. (1994) UK Patent Application GB 2291051 A.

Hufton JR, Mayorga S. and Sircar, S. (1999) Sorption Enhanced Reaction Process for Hydrogen Production. AIChemE Journal, February

Kato, M., Essaki, K., Yoshikawa, S., Nakagawa, K. and Uemoto, H. (2002) Novel $\mathrm{CO}_{2}$ Absorbents Using Lithium-Containing Oxides. 6th International Conference on Greenhouse Gas Control Technologies, Paper CAABP2, Kyoto, Japan.

Lin, S.Y., Suzuki, Y., Hatano, H. and Harada, M. (2002) Developing an Innovative Method HyPr-RING to Produce Hydrogen from Hydrocarbons. Energy Conversion and Management, 43, 9$12,1283$.

Lyngfelt, A., Leckner, B. and Mattisson, T. (2001) A FluidizedBed Combustion Process with Inherent $\mathrm{CO}_{2}$ Separation; Application of Chemical-Looping Combustion. Chemical Engineering Science, 56, 3101-3113.

Lyngfelt, A. and Thunman, H. (2004) Construction and $100 \mathrm{~h}$ of Operational Experience of a $10-\mathrm{kW}$ Chemical Looping Combustor. To Appear as Chapter 36 in: The $\mathrm{CO}_{2}$ Capture and Storage Project (CCP) for Carbon Dioxide Storage in Deep Geologic Formations For Climate Change Mitigation, 1: Capture and Separation of Carbon Dioxide From Combustion Sources. Thomas, D. (ed.) Elsevier Science, London.

Lyngfelt, A., Kronberger, B., Adanez, J., Morin, J.X. and Hurst, P. (2004) The GRACE Project. Development of Oxygen Carrier Particles for Chemical-Looping Combustion. Design and Operation of a $10 \mathrm{~kW}$ Chemical-Looping Combustor. 7th International Conference on Greenhouse Gas Control Technologies, Vancouver, Canada, 5th-9th September.

Marion, J., Mohn, N., Liljedahl, G.N., Nsakala, N., Morin, J.X. and Henriksen, P.P. (2004) Technology Options For Controlling $\mathrm{CO}_{2}$ Emissions From Fossil-Fuelled Power Plants. 3rd Annual Conference on Carbon Capture and Sequestration, May 3-6, Alexandria, VA, USA.
Nakagawa, K. and Ohashi, T. (1998) A Novel Method of $\mathrm{CO}_{2}$ Capture from High Temperature Gases. J. Electrochem. Soc., 145, 4, 1344-1346.

Nsakala, N., Liljedahl, G., Marion, J., Bozzuto, C., Andrus, H. and Chamberland, R. (2003) Greenhouse Gas Emissions Control by Oxygen Firing in Circulating Fluidized Bed Boilers. 2nd Annual Conference on Carbon Capture and Sequestration. May 5-8, Alexandria, VA, USA.

Ryu et al. (2004) Poster presented at the 7th International Conference on Greenhouse Gas Control Technologies, Vancouver, Canada, September 5-9.

Shimizu, T., Hirama, T., Hosoda, H., Kitano, K., Inagaki, M. and Tejima, K. (1999) A Twin Fluid-Bed Reactor for Removal of $\mathrm{CO}_{2}$ from Combustion Processes. Trans. I. Chem. E., 77-A, 62.

Silaban, A. and Harrison, D.P. (1995) High Temperature Capture of Carbon Dioxide: Characteristics of the Reversible Reaction between $\mathrm{CaO}$ (s) and $\mathrm{CO}_{2}(\mathrm{~g})$. Chem. Eng. Comm., 137, 177.

Simmonds, M., Miracca, I. and Gerdes, K. (2004) Oxyfuel Technologies for $\mathrm{CO}_{2}$ Capture: a Techno-Economic Overview. The 7th International conference on Greenhouse Gas Control Technologies, Vancouver, Canada, September 5-9.

Sundkvist, S.G., Griffin, T. and Thorshaug, N.P. (2001) AZEP Development of an Integrated Air Separation Membrane - Gas Turbine. Second Nordic Minisymposium on Carbon Dioxide Capture and Storage, Chalmers University of technology, Göteborg, Sweden, October 26.

Sundkvist, S.G., Klang, Å., Sjödin, M., Wilhelmsen, K., Åsen, K., Tintinelli, A., McCahey, S. and Ye, H. (2004) AZEP Gas Turbine Combined Cycle Power Plants - Thermal Optimisation and LCA Analysis. The 7th International Conference on Greenhouse Gass Control Technologies, Vancouver, Canada, September 5-9.

Van der Sluijs, J.P., Hendriks, C.A. and Blok, K. (1992) Feasibility of Polymer Membranes for Carbon Dioxide Recovery from Flue Gases. Energy Convers. Mgmt., 33, 5-8, 429-436.

Wang, J., Anthony, E.J. and Abanades, J.C. (2003) A Simulation Study for Fluidized Bed Combustion of Petroleum Coke with $\mathrm{CO}_{2}$ Capture. 17th Int. Conf. on Fluidized Bed Combustion, ASME, Jacksonville, FL, USA.

Ziock, H.J., Brosha, E.L., Garzon, F.H., Guthrie, G.D., Mukundan, R., Robinson, T.W., Roop, B., Smith, B.F., Johnson, A.A., Lackner, K.S., Lau, F., Anthony, E.J., Wang, J. and J. Ruby (2002) Technical Progress in the Development of Zero Emission Coal Technologies, 19th Annual Pittsburgh Coal Conference, Pittsburgh, PA, USA. 